\title{
A RETROSPECTIVE CLINICAL STUDY OF PULMONARY DISEASE DUE TO "ANONYMOUS MYCOBACTERIA" IN WALES
}

\author{
BY \\ S. R. KAMAT,* C. E. ROSSITER, AND J. C. GILSON \\ From the Pneumoconiosis Research Unit of the Medical Research Council, Llandough Hospital, \\ near Penarth, Glamorgan
}

(RECEIVED FOR PUBLICATION MARCH 10, 1961)

As tuberculosis decreases in frequency, more attention is being given to other bacteria causing similar chronic granulomatous lesions in the lung. In the last 10 years lesions attributed to "anonymous mycobacteria" have been frequently discussed. Such organisms were isolated in occasional cases from the sputum, gastric washings, or pleural fluid of patients with pulmonary disease before the era of chemotherapy (Branch, 1933 ; Cummins and Williams, 1933; Pinner, 1935 ; Steenken and Landau, 1936; Baldwin, 1942 ; Feldman, Davies, Moses, and Andberg, 1943 ; Buckle and Tolhurst, 1948 ; Gibson, 1953). Feldman et al. (1943) described repeated isolation of this type of organism in a case of silicosis. Wood, Buhler, and Pollak (1956) reported a series of 15 cases, and recently Christianson and Dewlett (1960) 25 cases from Texas. In Great Britain, Young (1955) reported the first fatal case, and Nassau and Hamilton (1957) presented a series of 18 cases.

The pathology of this disease is very similar to that of tuberculosis. Anonymous mycobacteria can also cause infection of various other sites, and the scotochromogen strains (see below) have been isolated from cervical lymph nodes (Runyon, 1959a ; Chapman and Guy, 1958; Prissick and Masson, 1956).

Middlebrook (1956) in the U.S.A. puts the incidence of anonymous strains in his cultures of mycobacteria at $1 \%$. In Britain it was reported to be about $0.6 \%$ (Mitchison and Selkon, 1957) and $2 \%$ by Marks and Trollope (1960a).

Jenkins (1959) suggested the following criteria for diagnosis of disease caused by anonymous mycobacteria: (1) Isolation of the organism in the absence of other mycobacteria ; (2) repeated isolation of the same organism (single positive

\footnotetext{
* Now at Tufts University School of Medicine, Boston City
} Hospital, Boston 18, Mass. cultures are of less significance); (3) demonstration of the anonymous organism by culture of resected material; (4) (a) stronger reaction to homologous purified protein derivative (P.P.D.) compared with standard tuberculoprotein ; $(b)$ the presence of specific antibodies as demonstrated by agar gel diffusion techniques in patients' serum ; (5) correlation of the isolation with clinical features.

Bacteriologically, anonymous strains are distinctive but somewhat heterogeneous. The most commonly used classification is that of Runyon (1959a). This has been modified by Marks and Trollope (1960a), who divide the bacilli into: Type I, photochromogens, which are mostly pathogenic ; type II, scotochromogens, which can seldom be incriminated in human disease; type III, non-chromogens, which are more heterogeneous than the other two types.

This classification, though not entirely satisfactory from the clinical viewpoint, is the best available to reconcile clinical and bacteriological features.

Pretherapy drug resistance and limited or absent pathogenicity to guinea-pigs are two of the characteristics of the group as a whole. Jenkins (1959) has reported details of their resistance to drugs in culture. Runyon (1959b) investigated their virulence in animals; none of the 100 strains tested produced progressive disease in guinea-pigs. All of the seven type I strains and 36 of 78 type III strains were pathogenic to mice, but none of the type II strains. Local abscess formation and mild sensitization to tuberculin were common.

Mankiewicz (1958) and Lester, Colton, Parlett, and Youmans (1960) summarize experience with agar gel diffusion tests on sera of patients affected by anonymous bacteria. Runyon (1959b) concludes that techniques are not as yet sufficiently refined to obtain dependably specific precipitin- 
type reactions. Skin tests with various tuberculins derived from different strains have been studied in animals (Affronti, 1959), and their application in man has been reviewed by Edwards and Edwards (1960). The epidemiological aspects in contacts have been described by Crow, King, Smith, Corpe, and Stergus (1957). The origin and mode of spread of these organisms are uncertain.

We had a clinical impression that these bacilli might be more frequent in coalworkers, especially those with complicated pneumoconiosis. We wanted to know more about the importance of isolation of these bacilli, and the course of the infections for which they might be responsible.

\section{Material AND Methods}

Anonymous Group.-Dr. J. Marks, of the Tuberculosis Reference Laboratory, Cardiff, has been interested in the problem and has kept a watch on new isolations over a number of years. The bacteriological study of this material has been published recently (Marks and Trollope, 1960a, b, c). We decided to extend the study on the clinical aspect.

All the patients showing repeated isolations of anonymous mycobacteria between early 1952 and 1960 (first four months) are included. There were 59; the only two women were excluded, leaving a group of 57 men for study. Each isolation of anonymous bacilli was the result of culture of sputum sent to diagnose or exclude tuberculosis. All atypical cultures were studied further and their types decided. An additional 18 patients with a single positive isolation were also available; these included 16 miners and two non-miners. These cases are briefly discussed later.

Control Group. - In a disease so similar, it seemed desirable to compare our group with a control group suffering from tuberculosis. Such a comparison might provide interesting information on relationships to occupation, age, and relative morbidity.

About 3,500 samples are cultured by the Tuberculosis Reference Laboratory each month. For each anonymous case a control was chosen at random from among the men with typical tubercle bacilli isolated for the first time at the Laboratory at about the same date. Reserve controls were selected in case the first control was not available for study, but very few were needed. The controls were not matched for age or occupation. This gave us a control group of 57 cases. In both these groups the first positive sputum isolations were those at the Tuberculosis Reference Laboratory, but this did not mean that the cases had not been diagnosed previously elsewhere. In fact, the control group has more cases which were diagnosed in earlier years.

SUBGROUPS.-Each group of 57 was divided into $A$ and B subgroups. Subgroup A showed radiological evidence of pneumoconiosis of Category 1 or more according to the I.L.O. classification (International
Labour Organization, 1953). Subgroup B included miners showing no radiological evidence of pneumoconiosis and all the non-miners. A "miner" was defined as a person who had worked at least one year underground in a mine.

SOURCE OF INFORMATION. - Information was obtained about the total of 114 patients (57 anonymous and 57 controls) from chest clinics, hospitals, pneumoconiosis medical panels of the Ministry of Pensions and National Insurance which a majority of the miners had attended, records of sputum cultures from the Tuberculosis Reference Laboratory, questionnaires sent to the chest clinics about examination of contacts, and questionnaires sent to all the living patients inquiring about their working history since the year of diagnosis.

Chest Radiographs.-All available films were examined, and a special study was made in each case of the first film, the one at the time of diagnosis, and the last one available. From these three posteroanterior films the area of the lesion was traced on to tissue paper without the identification information being available; subsequently the areas were measured on squared paper in square centimetres. It was thought that the method of measuring the change of area of lesion was likely to be more accurate than gross reading (see Cochrane, Moore, and Thomas, 1961). Two sample studies were done later to assess any bias in these measurements. The areas of the shadows were traced from the films without know ledge of the date of the film or the group to which it belonged. The results of both studies agree. There are differences in absolute readings, but there was no significant bias in the readings as between control and anonymous groups. All measurements were done by S.R.K. Thus it is unlikely that differences in the change of size of lesion between the anonymous and control groups with time are due to observer variability.

ConTACTS.-The information was obtained about the health of the contacts from the clinic notes, and the special questionnaire to the clinics.

LOSS OF WoRK.- In an attempt to assess the time off work from chest illness, each patient was sent a questionnaire through his chest clinic, asking him to record year by year since first diagnosis the time spent $(a)$ off work, $(b)$ in light work, and $(c)$ in full work.

\section{RESULTS}

Age, Occupation, and Year of Diagnosis.Table I shows the mean ages, the proportion of miners, and the year of diagnosis in the two groups. The age is taken as that at the time of diagnosis; the year of diagnosis is the date when a presumptive diagnosis of tuberculosis was made. Some patients in the control series had a positive sputum detected a little after the diagnosis made from clinical and radiological evidence. The 
TABLE I

AGE, OCCUPATION, AND YEAR OF DIAGNOSIS

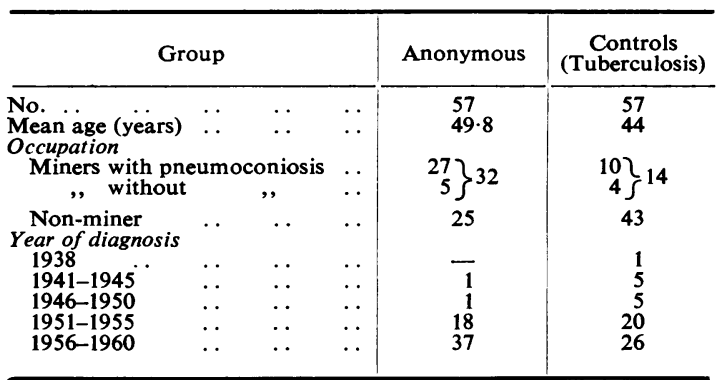

Notes: Miners are those with $>$ one year's mining experience. Those with pneumoconiosis are those with radiological evidence of category 1 or more (I.L.O. Classification, 1950).

average age for the anonymous group is 49.8 years, and 44 years for the control group. The control group has more young men; there are 18 patients below 35 years but only seven below this age in the anonymous group. However, the age distributions for the two groups are not statistically significantly different, nor are they within the subgroups with and without pneumoconiosis.

The proportion of miners differs in the two groups. There are 32 miners in the anonymous group but only 14 in the control group. Also there are 27 with pneumoconiosis (category 1 and more) in the anonymous group and only 10 in the control group. These differences are significant $(\mathrm{P}<0.001)$.

There were also differences in the year of diagnosis. Eleven of the control group were diagnosed before 1951, but only two of the anonymous group. These differences may be real, for example, caused by a shorter course of anonymous infection either by early death or recovery. But it may also be due, at least in part, to imperfections of the records. To reject those patients from the controls who were diagnosed a number of years before a positive sputum was obtained would introduce a bias into the method of selection, and it was decided to include them in the analysis, but their presence makes some of the comparisons between the groups less satisfactory than we hoped. This difference between the groups reveals a difficulty in interpreting retrospectively collected material of this type, especially when it spans an era of rapid development of chemotherapy.

If we accept that the two groups are comparable by virtue of this unbiased selection from the records, then there is a significant difference in the date of diagnosis between those with anonymous infection and those with tuberculosis $(P<0.05)$.
Contribution to Clinical Symptoms by ANONYMous BaCilli.-An attempt was made to decide whether the presence of anonymous bacilli could be considered responsible for contributing to the symptoms. The criteria used to decide this were (1) sudden increase in symptoms or haemoptysis at the time of the isolation; (2) general deterioration in the patient's condition which is not explained by other factors, especially if this improves rapidly after institution of treatment. This information was assessed without knowledge of the type of anonymous bacillus present, or whether the man had pneumoconiosis.

Table II shows an analysis of this information. It does not, of course, indicate patients in whom the organism is causing disease without symptoms. In about three-quarters of the patients we thought that the infection was causing symptoms and the presence of pneumoconiosis did not increase the frequency of symptoms.

TABLE II

PATIENTS IN ANONYMOUS GROUP WITH CLINICAL EVIDENCE INDICATING SYMPTOMATIC OR ASYMPTOMATIC INFECTION

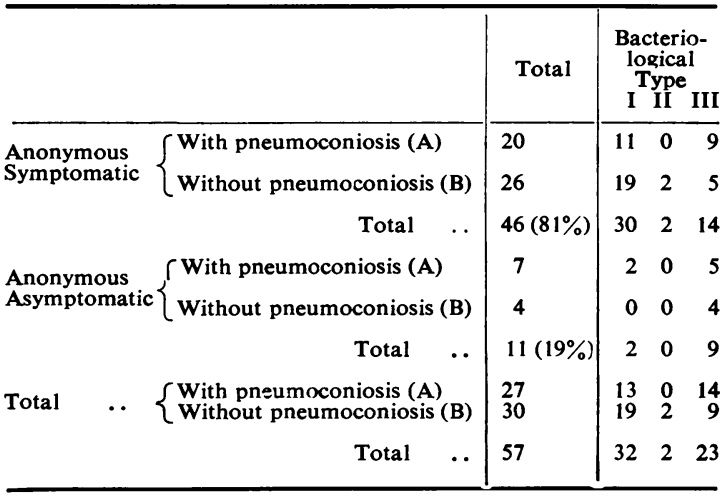

Table II also gives the distribution of cases according to the bacteriological types. Nine out of 23 non-chromogen (type III) strains were considered asymptomatic clinically, but only two out of 34 chromogen strains (types I and II) $(\mathrm{P}<0.01)$. In those with pneumoconiosis, 14 out of 27 were type III compared with nine out of 30 in those without pneumoconiosis, but these differences are not statistically significant.

Period of Observation and Clinical FeAtures.-Table III gives the mean duration of observation for the patients in the four subgroups. This is calculated from the month of diagnosis to the last month for which information was available. On the average, the controls were observed 
TABLE III

PERIOD OF OBSERVATION, INCIDENCE OF HAEMOPTYSIS AND BRONCHITIS, AND ERYTHROCYTE SEDIMENTATION RATE IN ANONYMOUS AND CONTROL (TUBERCULOSIS) GROUPS

\begin{tabular}{|c|c|c|c|c|c|c|c|c|}
\hline & & \multirow{2}{*}{ No. } & \multirow{2}{*}{$\begin{array}{l}\text { Obervation } \\
\text { Months } \\
\text { (Mean) }\end{array}$} & \multirow{2}{*}{ Haemoptysis } & \multirow{2}{*}{ Bronchitis } & \multicolumn{3}{|c|}{ E.S.R. (Westergren mm./1 hr.) } \\
\hline & & & & & & $<15$ & $>15$ & No Record \\
\hline \multirow{2}{*}{ Anonymous } & With pneumoconiosis (A) & 27 & $34 \cdot 1$ & $16(59 \%)$ & $24(89 \%)$ & 3 & 11 & 13 \\
\hline & Without pneumoconiosis (B) & 30 & $\begin{array}{c}47 \cdot 7 \\
(1-167)\end{array}$ & $13(43 \%)$ & $11(37 \%)$ & 4 & 16 & 10 \\
\hline \multirow{4}{*}{ Control } & Total & 57 & $41 \cdot 3$ & $29(51 \%)$ & $35(61 \%)$ & 7 & $27(79 \%)$ & 23 \\
\hline & With pneumoconiosis (A) & 10 & $\begin{array}{c}52 \cdot 4 \\
(1-108)\end{array}$ & $4(40 \%)$ & $5(50 \%)$ & 1 & 7 & 2 \\
\hline & Without pneumoconiosis (B) & 47 & $\begin{array}{c}(1-100) \\
68 \cdot 8 \\
(2-252)\end{array}$ & $11(23 \%)$ & $21(45 \%)$ & 17 & 18 & 12 \\
\hline & Total & 57 & $65 \cdot 9$ & $15(26 \%)$ & $26(45 \%)$ & 18 & $25(58 \%)$ & 14 \\
\hline
\end{tabular}

for a longer period (65.9 months) than those with anonymous infection (41.3 months). This is partly due to more numerous chronic patients in the control group. Many anonymous patients not being regarded as of such gravity were apparently not followed up with the same vigour. There is a wide range of period of observation in all groups.

In a retrospective study we did not think it useful to compare the type of onset, incidence, and duration of cough or dyspnoea, and so these aspects are not considered further: quite often chronic bronchitis could account for these symptoms.

The incidence of haemoptysis $(51 \%)$ recorded in the case notes was higher in the anonymous group and this difference is significant $(\mathrm{P}<0.05)$; but there are no significant differences between the subgroups. As the anonymous group was observed over a shorter average time than the control group this may be an underestimate of the relative incidence of this symptom.

Chronic bronchitis and emphysema were commonly recorded in the notes, and in a few cases bronchiectasis. Table III shows that bronchitis was more often noted in the anonymous series, and in those with pneumoconiosis in both groups.

The first E.S.R. recorded soon after diagnosis was analysed. A reading below $15 \mathrm{~mm}$./ hr. was considered normal. Twenty-seven $(79 \%)$ of the anonymous cases and $25(58 \%)$ controls had a raised E.S.R., but E.S.R. readings were available in only about $70 \%$ of patients.

SPutum STudies.-Table IV gives results of the drug sensitivity tests on the bacteria isolated from the sputum in the two groups. The sensitivities are given in three categories: (1) Fully sensitive, (2) doubtfully sensitive, (3) resistant including partially resistant strains. The difference between the anonymous and control groups is striking.

Out of 41 strains in which sensitivities were studied in the anonymous group, 31 were totally resistant to the three major drugs and another nine were resistant to two major drugs. Thus routine chemotherapy with standard drugs would appear irrational in 40 out of 41 patients. On the other hand, out of 53 strains from the control group, 49 were sensitive to two major drugs.

The sensitivities to other drugs were also carried out in a number of cases. All the anonymous strains were resistant to pyrazinamide and terra mycin. Variable patterns were found to cycloserine and viomycin: more details are given by Marks and Trollope (1960b). Most of the control strains tested against these four drugs proved sensitive.

TABLE IV

DRUG SENSITIVITIES OF MYCOBACTERIA CULTURED FROM SPUTUM OF ANONYMOUS AND CONTROL (TUBERCULOSIS) GROUPS

\begin{tabular}{|c|c|c|c|c|c|}
\hline & $\begin{array}{c}\text { Drug } \\
\text { Sensitivities }\end{array}$ & $\begin{array}{l}\text { Fully } \\
\text { Sensi- } \\
\text { tive }\end{array}$ & $\begin{array}{l}\text { Doubt- } \\
\text { fully } \\
\text { Sensi- } \\
\text { tive }\end{array}$ & $\begin{array}{c}\text { Resistant } \\
\text { Including } \\
\text { Partially } \\
\text { Resistant }\end{array}$ & Total \\
\hline Anonymous & $\left\{\begin{array}{lc}\text { Streptomycin } \\
\text { P.A.S. } & \ldots \\
\text { INAH } & \cdots\end{array}\right.$ & $\begin{array}{l}1 \\
1 \\
2\end{array}$ & $\frac{7}{1}$ & $\begin{array}{l}33 \\
40 \\
38\end{array}$ & $\begin{array}{l}41 \\
41 \\
41\end{array}$ \\
\hline Control & $\left\{\begin{array}{l}\text { Streptomycin } \\
\text { P.A.S. } \\
\text { INAH }\end{array}\right.$ & $\begin{array}{l}46 \\
49 \\
47\end{array}$ & $\underline{2}$ & $\begin{array}{l}5 \\
4 \\
6\end{array}$ & $\begin{array}{l}53 \\
53 \\
53\end{array}$ \\
\hline
\end{tabular}

Two patients from the anonymous group also had tuberculosis: in one, a resection for tuberculosis was made and type III anonymous bacteria were isolated from the specimen. In 12 anonymous cases sensitivity tests were done after some treatment, but the pattern of sensitivity did not appear different from that in the other cases.

In the 32 type I patients, $15(47 \%)$ converted ; of the 17 with persistent positive sputum, five died. Both type II patients converted. In the 23 type III 
patients, nine (39\%) converted ; and of the 14 with persistent positive sputum, seven died. Type I strains were more sensitive to streptomycin and cycloserine than the other types.

In the control group, in 16 patients sensitivity tests were done after some treatment; nine strains were sensitive to three drugs. In seven cases treatment could have been responsible for the resistance observed (six of these occurred before 1954). Five additional cases which showed resistance to at least one major drug did so before any chemotherapy.

Response to Medical Treatment.-Table V shows response to treatment, which usually meant giving two of the three standard drugs. The four anonymous patients who converted without treatment were all considered asymptomatic and there was no radiological evidence of disease. In the anonymous group longer treatment was associated with a higher conversion rate, apparently irrespective of the drug sensitivity in these cases.

In the control group there was no apparent relation between length of treatment and conversion. This may be explained by the fact that persistent cases include more patients with chronic tuberculosis, in whom longer treatment has not made much difference.

In the anonymous group 22 out of $44(50 \%)$ converted on treatment, while in the control group 43 out of $56(77 \%)$ have converted. There are more young patients in the control series, but there are also more chronic cases. In order to assess which of these two factors is the more important the converted patients were analysed by age. In the anonymous group younger than 45 years of age,
14 out of $18(78 \%)$ converted, while in the older age group only 12 out of $39(31 \%)$ converted. Thus age is probably an important factor.

In the control group below the age of 45,25 out of $27(93 \%)$ converted and 18 out of $30(60 \%)$ converted in the older age groups. This may indicate that age plays a factor in conversion, though this does not explain the difference in conversion between the anonymous and control groups.

One anonymous patient from group A was first diagnosed in 1954. He was treated, and sputum converted along with clinical improvement. He relapsed in 1959 when culture revealed the same strain. He is not now treated as far as is known, and a positive sputum persists. In the anonymous group conversion was significantly more frequent in those without pneumoconiosis $(P<0.001)$. The proportion of cases that responded to treatment in the control group was higher than in the anonymous group and the difference is significant $(\mathrm{P}<0.01)$.

Sputum Conversion Times.-Table VI shows the time taken to convert the sputum to negative without subsequent relapse after the start of chemotherapy. This definition is accepted in order to minimize the effect of some of the cases in the control group being diagnosed earlier than the start of chemotherapy. In spite of anonymous bacilli being resistant to the common drugs, these patients convert on the average in a somewhat shorter time than those with tuberculosis. The conversion time was in general much longer in those treated before 1954 than in those starting treatment since that date. The four untreated patients in the anonymous group without evidence

TABLE V

BACTERIOLOGICAL RESPONSE TO TREATMENT

\begin{tabular}{|c|c|c|c|c|c|c|c|}
\hline & & & \multirow[b]{2}{*}{ Total } & \multicolumn{2}{|c|}{ Converted to Negative } & \multicolumn{2}{|c|}{ Persistent Positive } \\
\hline & & & & No. & $\begin{array}{l}\text { Average Period of } \\
\text { Treatment (mth.) }\end{array}$ & No. & $\begin{array}{l}\text { Average Period of } \\
\text { Treatment (mth.) }\end{array}$ \\
\hline \multirow{5}{*}{ Anonymous } & \multirow{2}{*}{ With pneumoconiosis } & $\int$ Not treated & 10 & 2 & 一 & 8 & - \\
\hline & & Treated & 17 & 4 & $18 \cdot 3$ & 13 & $9 \cdot 2$ \\
\hline & \multirow{3}{*}{ Without pneumoconiosis } & $\int$ Not treated & 3 & 2 & - & 1 & - \\
\hline & & Treated & 27 & 18 & 14.9 & 9 & $6 \cdot 3$ \\
\hline & & Total & 57 & 26 & & 31 & \\
\hline \multirow{5}{*}{ Control } & \multirow{2}{*}{ With pneumoconiosis } & Not treated & 一 & 一 & 一 & 一 & - \\
\hline & & Treated & 10 & 6 & $19 \cdot 1$ & 4 & $15 \cdot 0$ \\
\hline & \multirow{3}{*}{ Without pneumoconiosis } & $\int$ Not treated & 1 & - & - & 1 & 一 \\
\hline & & Treated & 46 & 37 & $19 \cdot 2$ & 9 & $19 \cdot 6$ \\
\hline & & Total & 57 & 43 & & 14 & \\
\hline
\end{tabular}


of chest disease converted in an average of 8.8 months.

It is rather academic to consider average times before conversion, as the plotted distribution of these times is U-shaped. However, considering the proportions of people who converted in six months or in 12 months there are no significant differences between different subgroups.

TABLE VI

SPUTUM CONVERSION TIMES*

\begin{tabular}{|c|c|c|c|c|c|}
\hline & & \multicolumn{4}{|c|}{ Treated } \\
\hline & & \multicolumn{2}{|c|}{ Before 1954} & \multicolumn{2}{|c|}{$\begin{array}{l}1954 \text { and } \\
\text { Onwards }\end{array}$} \\
\hline & & No. & $\underset{\text { (mime }}{\text { Av. }}$ & No. & $\underset{\text { (mime }}{\text { Av. }}$ \\
\hline \multirow{3}{*}{ Anonymous } & With pneumoconiosis & - & - & 4 & $5 \cdot 8$ \\
\hline & Without pneumoconiosis & 4 & $37 \cdot 5$ & 14 & $4 \cdot 5$ \\
\hline & Total 57 & 4 & & 18 & \\
\hline \multirow{3}{*}{ Control } & With pneumoconiosis & 2 & $58 \cdot 0$ & 4 & $18 \cdot 0$ \\
\hline & Without pneumoconiosis & 8 & $40 \cdot 9$ & 29 & $6 \cdot 8$ \\
\hline & Total 57 & 10 & & 33 & \\
\hline
\end{tabular}

* Time from start of chemotherapy to first negative sputum without subsequent relapse.

Radiological Features.-Tables VII, VIII, and IX summarize the analysis of radiological findings. The radiographs were traced and areas of the shadows were measured in square centimetres.

Types of Lesion.-Table VII shows that in those without pneumoconiosis there is a higher proportion of unilateral lesions in the anonymous group $(46 \%)$ than in the control group $(23 \%)$. Also that in both groups those with pneumoconiosis more often have bilateral lesions.

The anonymous group shows a higher incidence of cavitation $(72 \%)$ than the control group (51\%), and in the anonymous group those with pneumo- coniosis seem to cavitate a little more often than those without pneumoconiosis. Statistically there is no significant difference between the anonymous and control groups as regards the type of lesion, unilateral or bilateral, but the proportion of bilateral cases in group $\mathbf{A}$ is significantly higher than in group $B(P<0.01)$.

The incidence of cavitation does not differ significantly between subgroups A and B in both series, but the incidence of cavitation in the anonymous group is significantly higher than in the control group $(\mathrm{P}<0.02)$. In the anonymous group, and especially in those without pneumoconiosis, the lesions tended to be restricted to the upper half of the lung fields.

Changes in Radiological Lesions.-In judging the progress of the radiological lesion, the first available radiograph on diagnosis was taken as a base line. Any change in total area within the range of $\pm 10 \%$ was recorded as unchanged. If the area increased in the last available radiograph beyond $10 \%$, then the shadow is recorded as being radiologically worse. This simplified analysis inevitably obscures temporary improvements followed by a relapse. In those who underwent surgery, the last film is the one taken just before the surgery. In view of the complicating post operative factors, the analysis of the change was. not carried further. In a few patients (four in the anonymous and three in the control group) adequate follow-up films were not available.

Table VIII shows that there was a reduction in shadow area in $78 \%$ of the control group but in only $54 \%$ of the anonymous group. This difference is not statistically significant, but the greater improvement of the control group without pneumoconiosis compared with those in the anonymous group also without pneumoconiosis is significant $(\mathrm{P}<0.05)$. A fifth of the anonymous group showed progression of the lesions compared with only one-tenth of the controls.

TABLE VII

TYPE OF RADIOLOGICAL LESION IN ANONYMOUS AND CONTROL (TUBERCULOSIS) GROUPS

\begin{tabular}{|c|c|c|c|c|c|c|c|}
\hline & & & & & Unilateral & Bilateral & Cavity \\
\hline \multirow{3}{*}{ Anonymous } & With pneumoconiosis (A) & . & . & . & $3(11 \%)$ & $23(89 \%)$ & $21(78 \%)$ \\
\hline & Without pneumoconiosis (B) & . & $\ldots$ & . & $13(46 \%)$ & $15(54 \%)$ & $20(69 \%)$ \\
\hline & & & & Total $54^{*}$ & $16(30 \%)$ & $38(70 \%)$ & $41(72 \%)$ \\
\hline \multirow{3}{*}{ Control } & With pneumoconiosis (A) & . & $\cdots$ & . & $1(10 \%)$ & $9(90 \%)$ & $5(50 \%)$ \\
\hline & Without pneumoconiosis (B) & . & $\ldots$ & . $\quad \ldots$ & $11(23 \%)$ & $36(77 \%)$ & $24(51 \%)$ \\
\hline & & & & Total $57^{*}$ & $12(22 \%)$ & $45(79 \%)$ & $29(51 \%)$ \\
\hline
\end{tabular}


TABLE VIII

PERCENTAGE CHANGE IN AREA OF RADIOLOGICAL SHADOWS OF ANONYMOUS AND CONTROI (TUBERCULOSIS) GROUPS

\begin{tabular}{l}
\hline \\
\hline
\end{tabular}

* In three patients there were no radiological abnormalities in the chest films.

Relation between Radiographic Improvement and Sputum Conversion.-Table IX relates the radiological change with sputum conversion. It shows that reduction in shadow areas is associated with sputum conversion in both the anonymous and control groups, but the relation is less close in the anonymous group. It also shows that, in those with no change or an increase in area, threequarters still had a positive sputum. Details of one patient presenting an unusual radiological picture are worth mentioning.

D. E. T. G., a man aged 39, a non-miner, was admitted to hospital in April, 1953, with pyrexia, loss of weight, and erythema nodosum ; a chest radiograph four weeks later suggested enlargement of right hilar glands. The Mantoux test was positive in June, 1953. He was discharged after two weeks, apparently improved, but continued to get cough with expectoration, dyspnoea, lassitude, and night sweats. A chest radiograph in June, 1953, showed extension of soft lesions in the right lung (Fig. 1).

In August, 1953 (Fig. 2), a radiograph and tomograms showed bilateral hilar adenopathy with some bilateral parenchymal shadows. His sputum culture was positive in October, 1953, and remained positive until April, 1954. The organisms were nonchromogen (type III) strains. Antituberculous chemotherapy was started. The E.S.R., which was $20 \mathrm{~mm}$./ hr., came down to $4 \mathrm{~mm}$./hr., and the radiograph improved remarkably. Radiologically the area was reduced to an insignificant residue by August, 1954 (Fig. 3).

The repeated isolation of a non-chromogen in this case was thought to be incidental in the beginning. Scalene node biopsy did not show sarcoid, and the Kveim test was negative; a liver biopsy was not made. In view of the history of preceding erythema nodosum, fever, and response to antituberculous therapy, we think this man's disease was probably related to the anonymous infection. The radiograph is unusual, and resembles sarcoidosis. This picture of bilateral hilar adenopathy, erythema nodosum, and sarcoid-like radiographic shadows which improved after treatment has not been reported previously in anonymous infections.

RESUlTS OF SURGERY.-Eight of the anonymous group were treated surgically (seven resections); of these, seven converted (88\%) and surgery was considered important in producing conversion in five of them, one having tuberculosis as well. The

TABLE IX

RELATION OF CHANGE OF AREA OF SHADOW TO SPUTUM CONVERSION

\begin{tabular}{|c|c|c|c|c|c|c|}
\hline & & & \multicolumn{2}{|c|}{ Unchanged or Increased } & \multicolumn{2}{|c|}{ Reduction } \\
\hline & & & Persistent Positive & $\begin{array}{l}\text { Converted to } \\
\text { Negative }\end{array}$ & Persistent Positive & $\begin{array}{c}\text { Converted to } \\
\text { Negative }\end{array}$ \\
\hline \multirow{3}{*}{ Anonymous } & With pneumoconiosis (A) & . & 12 & 2 & 8 & 3 \\
\hline & Without pneumoconiosis (B) & ... & 5 & 2 & 3 & 15 \\
\hline & & Total & $17(80 \%)$ & $4(20 \%)$ & $11(40 \%)$ & $18(60 \%)$ \\
\hline \multirow{3}{*}{ Control } & $\int$ With pneumoconiosis (A) & . & 5 & 1 & - & 3 \\
\hline & Without pneumoconiosis (B) & . .. & 3 & 2 & 6 & 34 \\
\hline & & Total & $8(73 \%)$ & $3(27 \%)$ & $6(14 \%)$ & $37(86 \%)$ \\
\hline
\end{tabular}




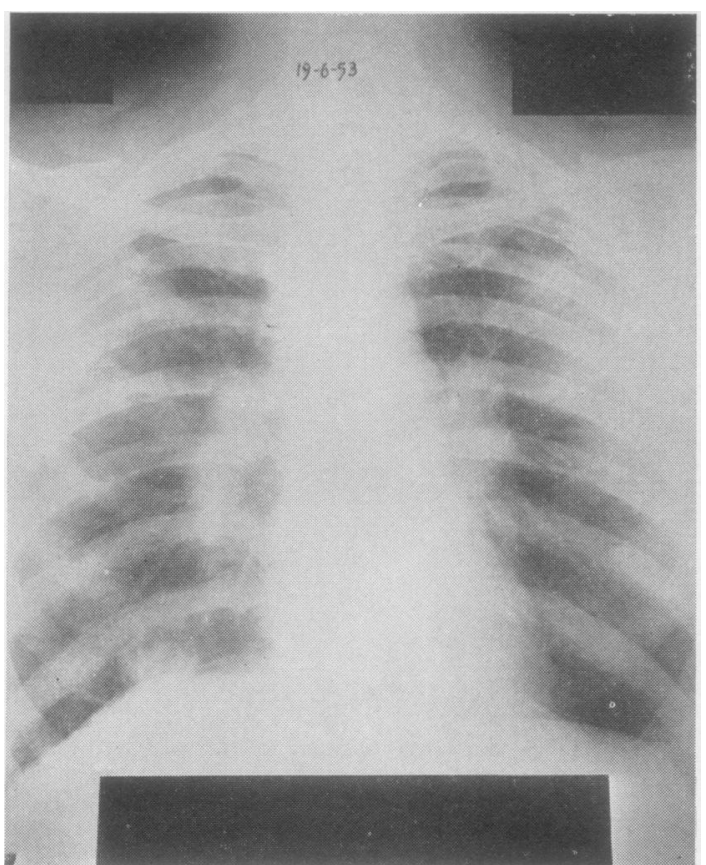

FIG. 1

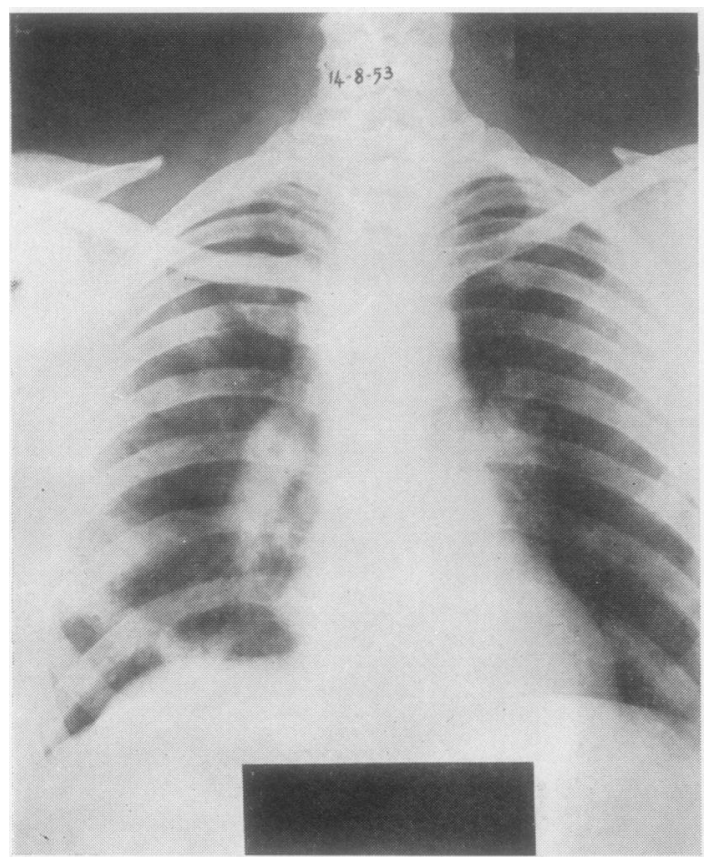

FIG. 2

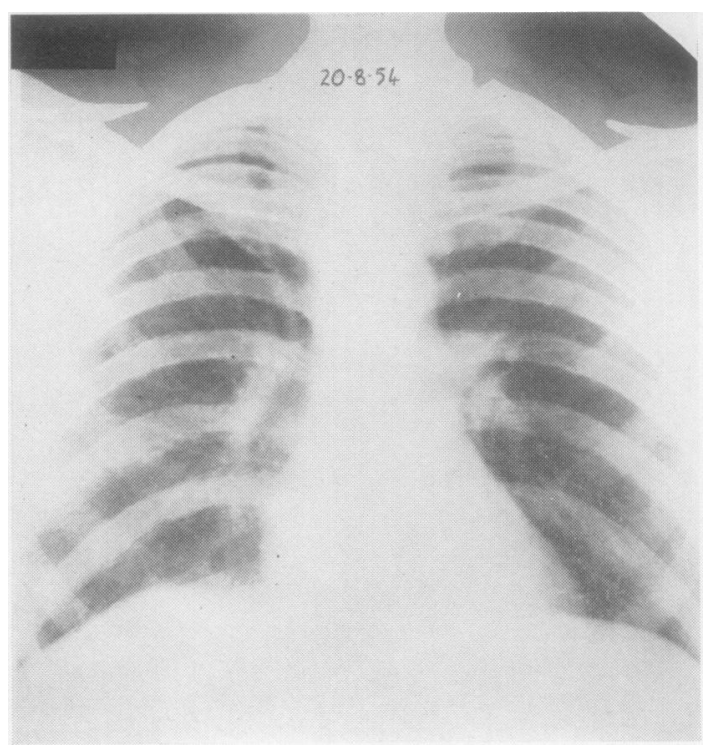

FIG. 3

histology of the resected specimens closely resembled tuberculosis in all cases. In the controb group 12 were treated by surgery (eighs resections) ; of these, 11 converted $(92 \%)$ and in these surgery was thought important as a cause of conversion in five.

DeATHS.-Table $X$ shows that in the anonymous group 13 men died $(23 \%)$. In the six on whom a necropsy was made, one had progressive massive fibrosis and five had lesions in the lung histologically indistinguishable from tuberculosis. In the control group nine men died $(16 \%)$. Necropsy information was available on only four; three showed tuberculosis and one P.M.F. Statistical analysis shows that deaths in the groups with pneumoconiosis are significantly higher than in those without pneumoconiosis $(\mathrm{P}<0.05)$, but deaths in the anonymous group are not significantly higher than in the control group.

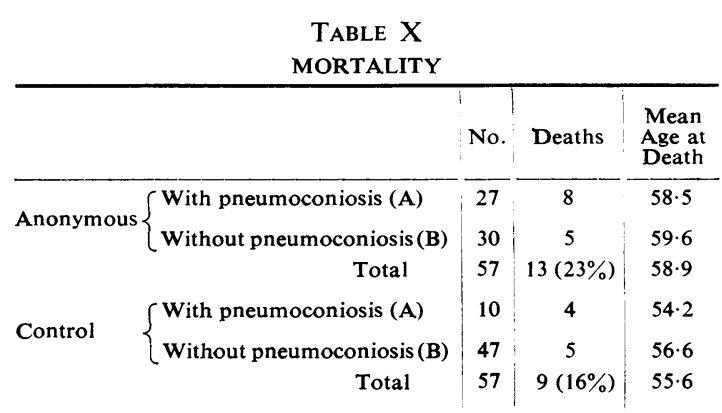


TABLE XI

CONTACT DATA

\begin{tabular}{|c|c|c|c|c|c|c|c|c|c|}
\hline & & \multirow{3}{*}{$\begin{array}{c}\text { No. of } \\
\text { Patients } \\
\text { with } \\
\text { Available } \\
\text { Infor- } \\
\text { mation }\end{array}$} & \multirow{3}{*}{$\begin{array}{c}\text { No. of } \\
\text { Patients } \\
\text { with } \\
\text { Contacts } \\
\text { Examined }\end{array}$} & \multirow{3}{*}{$\mid \begin{array}{c}\text { Total } \\
\text { No. of } \\
\text { Contacts }\end{array}$} & \multirow{3}{*}{$\begin{array}{c}\text { Average } \\
\text { No. of } \\
\text { Contacts } \\
\text { Per Case }\end{array}$} & \multirow{3}{*}{$\begin{array}{l}\text { Total No. } \\
\text { of Contacts } \\
\text { with Ra- } \\
\text { diographs } \\
\text { Suggestive } \\
\text { of Tuber- } \\
\text { culosis }\end{array}$} & \multicolumn{3}{|c|}{ Tuberculin Test } \\
\hline & & & & & & & \multirow{2}{*}{$\begin{array}{c}\text { No. of } \\
\text { Contacts } \\
\text { with Avail- } \\
\text { able In- } \\
\text { formation }\end{array}$} & \multicolumn{2}{|c|}{ Mantoux } \\
\hline & & & & & & & & Positive & Negative \\
\hline \multirow{2}{*}{ Anonymous (57) } & $\int$ With pneumoconiosis (A) & 25 & $15(60 \%)$ & 57 & $3 \cdot 8$ & 6 & 35 & 12 & 23 \\
\hline & Without pneumoconiosis (B) & 29 & $21(73 \%)$ & 56 & 2.7 & 3 & 24 & 8 & 16 \\
\hline \multirow{4}{*}{ Control (57) } & Total & 54 & $36(67 \%)$ & 113 & $3 \cdot 1$ & $9(8 \%)$ & 59 & $20(34 \%)$ & $39(66 \%)$ \\
\hline & With pneumoconiosis (A) & 9 & $6(67 \%)$ & 21 & $3 \cdot 5$ & $\mathbf{0}$ & 9 & 3 & 6 \\
\hline & Without pneumoconiosis (B) & 45 & $38(84 \%)$ & 147 & $4 \cdot 0$ & 23 & 58 & 21 & 37 \\
\hline & Total & 54 & $44(81 \%)$ & 168 & 3.9 & $23(14 \%)$ & 67 & $24(36 \%)$ & $43(64 \%)$ \\
\hline
\end{tabular}

CONTACTS.- - Hospitals and clinics from which the case sheets were obtained were asked to complete a questionnaire giving (1) How many contacts of the patient were examined? (2) How many of these showed radiographic evidence suggestive of tuberculosis? (3) Of any contacts tuberculin tested, how many were $(a)$ positive, $(b)$ negative? A little additional information was obtained from the case notes in a few cases. It was not thought possible to get more detailed information in the circumstances in this investigation, and, in assessing the high prevalence of radiographic abnormalities in the contacts, the limitations of this inquiry have to be remembered. We do not think that the returns will have been biased as between one group and another, though, as the results show, fewer contacts per case were examined in the anonymous group, as might be expected on account of the doubt formerly entertained about the clinical significance of a positive culture of anonymous mycobacteria.

Table XI shows the results of this questionnaire inquiry. In the anonymous group returns were obtained for 54 cases and in $67 \%$ of these contacts were examined, and the average number of contacts per patient was 3.1. Radiographic evidence suggestive of tuberculosis was reported in nine of the 113 contacts $(8 \%)$. Six of these cases were related to three propositi. In the control group information was also available in 54 cases, and contacts were examined in $81 \%$; the average number of contacts per case was 3.9. Radiographic evidence of tuberculosis (including one non-pulmonary case) was reported in 23 of the 167 contacts examined $(14 \%)$. The contacts of the control group have not a significantly higher proportion with radiological evidence of tuberculosis $(0.10>\mathrm{P}>0.05)$.

Information on tuberculin testing is less complete. Results were available in $52 \%$ of the contacts of the anonymous group and $40 \%$ of the contacts of the control group. There is no difference in the proportion of positive tuberculin reactions in the contacts of the two groups.

Loss OF WORK.-Table XII shows the results of the questionnaire sent through the clinics to the survivors of both groups, inquiring about time off work and whether in part-time or full-time employment. The replies reporting part-time work were too few for useful analysis. In the anonymous group replies were obtained in $84 \%$ of the patients, and the number of years off work was $39 \%$ of the total of 130 observation years. In the

TABLE XII

TIME OFF WORK IN SURVIVORS OF BOTH GROUPS

\begin{tabular}{|c|c|c|c|c|c|c|c|}
\hline & & & & & $\begin{array}{l}\text { No. of Cases with } \\
\text { Available Information }\end{array}$ & $\begin{array}{l}\text { Total No. of } \\
\text { Observation Years }\end{array}$ & $\begin{array}{l}\text { No. of Years off } \\
\text { Work }\end{array}$ \\
\hline \multirow{3}{*}{ Anonymous } & With pneumoconiosis (A) & . & . & .. & 16 & 48 & $23(48 \%)$ \\
\hline & Without pneumoconiosis (B) & . & . & .. $\quad \ldots$ & 21 & 82 & $28(34 \%)$ \\
\hline & . & & & Total & 37 & 130 & $51(39 \%)$ \\
\hline \multirow{3}{*}{ Control } & With pneumoconiosis (A) & $\cdots$ & $\cdots$ & $\cdots$ & 6 & 25 & $11(44 \%)$ \\
\hline & Without pneumoconiosis (B) & . & . & $\ldots \quad \ldots$ & 30 & 170 & $107(63 \%)$ \\
\hline & & & & Total & 36 & 195 & $118(61 \%)$ \\
\hline
\end{tabular}


control group replies were obtained in $72 \%$, and the time off work was higher, $61 \%$ of the period of observation. However, these differences are not statistically significant and there is no clear trend in the subgroups.

\section{Discussion}

During the past 10 years increasing importance has been attached to infection by anonymous mycobacteria, and it was our aim to make a quantitative clinical comparison with patients who had tuberculosis. The list of positive sputum cultures of tubercle bacilli and anonymous mycobacteria over a period of eight years, kept by Dr. J. Marks at the Tuberculosis Reference Laboratory in Cardiff, enabled us to select randomly a case of tuberculosis first proved at about the same time as the index case of anonymous infection. Those with tuberculosis were matched only for time of first isolation of bacilli and sex (all males).

Analysis of the two groups revealed that the interval between first diagnosis (often several years before bacteriological proof) and the first isolation of bacilli from the sputum was longer in the cases of tuberculosis than in those with anonymous infection. This difference may well be a real clinical difference between the two types of infection, but it may also in part be an artefact inherent in the imperfections of records. This difference in the two groups has to be remembered in assessing the significance of our findings. For example, as some patients with tuberculosis were first diagnosed in the early ' 50 s they were not treated as effectively as they would be now. This means that the tuberculosis group as a whole probably do not show as marked contrast in terms of morbidity and perhaps mortality as compared with the groups with anonymous infection as they might had the comparison been limited to cases recently diagnosed. Thus our study probably underestimates the clinical importance of these cases of anonymous infection.

There were only two women out of a total of 59 patients of anonymous infection collected by Dr. Marks over eight years, and it was for this reason that we restricted our comparison to males. A strikingly higher prevalence in males has also been reported by Jenkins (1959) and Christianson and Dewlett (1960), but Crow et al. (1957) reported that $28 \%$ of their cases were in women.

In our series the anonymous group tend to be older; in part this may be because there is in our area a close relationship between pneumoconiosis and infection by the anonymous bacteria; more than twice as many men in this group showed radiographic evidence of pneumoconiosis (category 1 or more) compared with those with tuberculosis. Jenkins (1959) stated that occupation is unrelated to infection by anonymous mycobacteria, but our results confirm the views expressed by Feldman et al. (1943), Dworski, Wilson, McCreary, Delahant, and Schepers (1957), and Schepers, Smart, Smith, Dworski, and Delahant (1958) of an association with pneumoconiosis. Those with pneumoconiosis were more often infected by type III (non-chromogen) strains. When compared with reports from Texas by Christianson and Dewlett (1960) and Jenkins, Babar, Chofnas, Foster, Barkley, Whitcomb, Foster, Jones, and McGee (1959) there is a much higher proportion of non-chromogen strains in our series.

In three out of the 57 cases of anonymous infection, no radiological lesions were detectable in the chest films, and they were asymptomatic. Nearly half the cases infected by type III strains were apparently asymptomatic whereas the great majority of those infected by photochromogens had symptoms of disease. Jenkins (1959) and Christianson and Dewlett (1960) found haemoptysis was the commonest presenting symptom in their series. We also find that this symptom is more frequent in the anonymous group than in the control group of patients with tuberculosis.

In two patients, anonymous infection was associated with bacteriologically proved tuberculosis. There was no history of any antituberculous chemotherapy in any of the remaining cases preceding the isolation of the anonymous mycobacteria. Thus it seems improbable that antituberculous therapy is a factor in causing the appearance of this type of infection in the individual in the circumstances of our investigation ; in this we confirm the findings of Christianson and Dewlett (1960).

The striking insensitivity of the anonymous mycobacteria to the three major antituberculous drugs has been reported by Marks and Trollope (1960b). Forty out of 41 strains isolated on more than one occasion were insensitive to two or more of the drugs. Nevertheless, many patients were treated with two of the three standard drugs. From this study it is not possible to state whether this was responsible for the $50 \%$ conversion of those in the anonymous group. Longer treatment was associated with a higher proportion with sputum conversion, and on present evidence it seems probable that chemotherapy should be tried. There is a need for controlled trials to establish the best method of treatment. Deaths occurred 
largely in those patients who did not convert. Surgery may be useful; a majority of those treated surgically converted.

A fairly objective index of radiographic changes was obtained by tracing and measuring the areas of the shadows. Nearly three-quarters of the anonymous group showed improvement (reduction of area greater than $10 \%$ ) compared with nine-tenths of those with tuberculosis. As might be expected, those with pneumoconiosis showed less improvement and the younger men improved more than the older ones. The anonymous infection more often produced unilateral lesions but with a higher proportion of cavities compared with the cases of tuberculosis. A high proportion with cavities, especially in relation to the area of the lesions, was noted by Christianson and Dewlett (1960).

It was not possible to obtain very detailed information about contacts. The percentage with suggestive evidence of tuberculosis in their chest films was higher in the control group, but was high in both groups. This was possibly due to the inclusion of some patients with healed primary lesions. The Mantoux-positive rates were similar in the contacts of the two groups. Beeuwkes, Hahn, and Putnam (1942) reported three times as high a positive rate in the contacts of tuberculosis compared with the group of anonymous cases. Crow et al. (1957) reported a radiological positive contact rate of $3 \%$ in those with anonymous mycobacteria compared to $44 \%$ in those with tuberculosis. Christianson and Dewlett (1960) also concluded that anonymous mycobacterial disease is less infectious than tuberculosis. In our series there were no instances of two patients with anonymous infection coming from the same home or even from the same area. Lewis, Lasche, Armstrong, and Dunbar (1960), in a study of 116 patients with infection by non-photochromogens, found no instances of cross-infection in the family or in hospital. The method of spread of this infection is still obscure.

We have been unable to trace any previous case in which anonymous infection was associated with bilateral hilar adenopathy, sarcoid-like radiographic appearance, and erythema nodosum. It is of interest that McCuiston and Hudgins (1960), studying the electrophoretic patterns of serum proteins in tuberculosis, sarcoidosis, and in anonymous infections, noted that the pattern in anonymous infection resembled more closely that of sarcoidosis than tuberculosis, although clinically and radiologically most of the anonymous infections closely resembled tuberculosis.
In 18 patients in whom single isolations only of anonymous bacilli were made, the majority (11) were type III. A number had complicated pneumoconiosis and in seven cavitation was present, but few of these men were clinically ill. There were three deaths; in two there was no evidence of tuberculosis at necropsy; one died of typical tuberculosis. Single isolations are probably not in themselves of great clinical significance but indicate the need for follow-up examination since some of the patients develop disease.

\section{SUMMARY}

A clinical study of 57 patients with anonymous mycobacterial infection collected through the Tuberculosis Reference Laboratory, Cardiff, between 1952 and 1960 is presented. These are compared with 57 similarly timed patients with tuberculosis. Brief information about 18 patients with single isolations of anonymous strains is also given.

There is a highly significant higher percentage of coal-miners with pneumoconiosis in the anonymous group. More than three-quarters of the anonymous group infections were thought to be causing symptoms clinically. Photochromogen type I strains were more frequently a cause of symptoms than non-chromogen type III. Haemoptysis was about twice as common in the anonymous group as in patients with tuberculosis. Those with tuberculosis were observed over a longer period and treated more vigorously.

Nearly all the anonymous strains were resistant to two or more of the major antituberculous drugs, but therapy with these drugs was used on a number of patients and probably had some effect. There was a significantly lower bacteriological conversion rate in the anonymous group than in those with tuberculosis, but the time to convert was not different.

Radiologically the anonymous lesions are similar to tuberculosis but have a higher proportion of cases with cavitation. Change of radiological appearance was assessed by measuring the area of the shadows. Improvement was more frequent in the tuberculosis group; in both groups, more frequent in those without pneumoconiosis. There was a good correlation between radiological improvement and sputum conversion. A patient is described with erythma nodosum, bilateral hilar adenopathy, and sarcoid-like radiographic lesions associated with type III anonymous mycobacteria in the sputum.

In the anonymous group there were more deaths, but the survivors had less time off work 
compared with the controls; the differences are not statistically significant.

In the anonymous group fewer of the contacts showed evidence of tuberculosis in the chest films, but there was no difference in the Mantouxpositive rates of the contacts of the two groups.

Significant isolations of anonymous mycobacteria occur in Wales, at present at the rate of about 1 per 100 new isolations of tubercle bacilli. The infection can produce a serious disease for which the best method of treatment is not yet established.

We wish to thank Dr. J. Marks for suggesting this inquiry, for his advice, and for allowing us to make use of his records. Professor A. L. Cochrane helped to plan the inquiry, and criticized the analysis. We are grateful to many chest physicians in clinics and hospitals throughout Wales who provided the material on which this analysis was made. and to Dr. R. W. Thomas, of the Pneumoconiosis Medical Panel of the Ministry of Pensions and National Insurance. for the loan of radiographs. We received much help from our colleagues, and especially Mr. B. J. Bonny, who undertook some of the statistical analysis.

\section{REFERENCES}

Affronti, L. F. (1959). Amer. Rev. Tuberc., 79, 284.

Baldwin, E. R. (1942). Ibid., 45, 756.

Beeuwkes, H., Hahn, R. G., and Putnam, P. (1942). Ibid., 45, 165.

Branch, A. (1933). Tubercle (Lond.), 14, 337.

Buckle, G., and Tolhurst, J. C. (1948). J. Path. Bact., 60, 116.

Chapman, J. S., and Guy, L. R. (1958). A.M.A. J. Dis. Child., 96, 496. Christianson, L. C., and Dewlett, H. J. (1960). Amer. J. Med., 29, 980.

Cochrane, A. L., Moore, F., and Thomas, J. (1961). Tubercle (Lond.), 42, 72 .
Crow, H. E., King, C. T. Smith, C. E., Corpe, R. F., and Stergus, I (1957). Amer. Rev. Tuberc, , i5, 199.

Cummins, S. L., and Williams, E. M. (1933). Tubercle (Lond.), 15, 49.

Dworski, M., Wilson, G. E., McCreary, H. W., Delahant, A. B., and Schepers, G. W. (1957). Industr. Med. Surg., 26, 536.

Edwards, P. Q., and Edwards, L. B. (1960). Amer. Rev. resp. Dis. 81, No. 2, Pt. 1: Supplement: Story of the Tuberculin Test from an Epidemiologic Viewpoint.

Feldman, W. H., Davies, R., Moses, H. E., and Andberg, W. (1943). Amer. Rev. Tuberc., 48, 82.

Gibson, J. B. (1953). J. Path. Bact., 65, 239.

International Labour Organization (1953). Proceedings of the Third International Conference of Experts on Pneumoconiosis. Sydney, Australia, 1950. International Labour Office, Geneva.

Jenkins, D. E. (1959). Bull. Un. int. Tuberc., 29, 295.

—_ Babar, D., Chofnas, I., Foster, R., Barkley, H. T., Whitcomb. F., Foster, M., Jones, E., and McGee, H. (1959). Paper presented at the National Tuberculosis Association annual meeting, Chicago, May 25, 1959.

Lester, W., Colton, R., Parlett, R. C., and Youmans, G. P. (1960). Amer. Rev. resp. Dis., 81, 954.

Lewis, A. G., Lasche, E. M., Armstrong, A. L., and Dunbar, F. P. (1960). Ann. intern. Med., 53, 273.

McCuiston, C. F., and Hudgins, P. C. (1960). Amer. Rev. resp. Dis., 82, 59.

Mankiewicz, E. (1958). Canad. J. Microbiol., 4, 565.

Marks, J., and Trollope, D. R. (1960a). Tubercle (Lond.), 41, 51. (1960b). Ibid., 41, 127. (1960c). Ibid., 41, 133.

Middlebrook, G. (1956). Bull. Un. int. Tuberc., 26, 179.

Mitchison, D. A., and Selkon, J. B. (1957). Tubercle (Lond.), 38, 85. Nassau, E., and Hamilton, G. M. (1957). Ibid., 38, 387.

Pinner, M. (1935). Amer. Rev. Tuberc., 32, 424.

Prissick, F. H., and Masson, A. M. (1956). Canad. med. Ass. J., 75, 798.

Runyon, E. H. (1959a). Med. Clin. N. Amer., 43, 273.

- (1959b). Bull. Un. int. Tuberc., 29, 396.

Schepers, G. W., Smart, R. H. Smith, C. R., Dworski, M., and Delahant, A. B. (1958). Industr. Med. Surg., 27, 27.

Steenken, W., and Landau, A. (1936). J. infect. Dis., 58, 247.

Wood, L. E., Buhler, V. B., and Pollak, A. (1956). Amer. Rev. Tuberc., 73, 917.

Young, R. D. (1955). Lancet, 2, 750. 